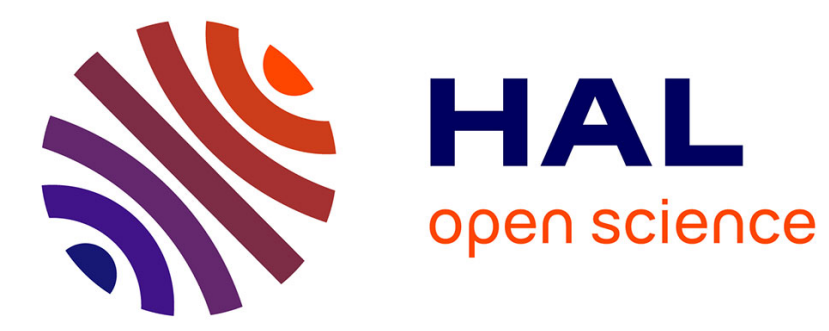

\title{
Fabrication and performance evaluation of reflectorless refractive index fiber optic sensors using etched enhanced backscattering fibers
}

\author{
A. Aitkulov, M. Sypabekova, C. Molardi, Wilfried Blanc, D. Tosi
}

\section{- To cite this version:}

A. Aitkulov, M. Sypabekova, C. Molardi, Wilfried Blanc, D. Tosi. Fabrication and performance evaluation of reflectorless refractive index fiber optic sensors using etched enhanced backscattering fibers. Measurement, 2021, 172, pp.108874. 10.1016/j.measurement.2020.108874 . hal-03137140

\author{
HAL Id: hal-03137140 \\ https://hal.science/hal-03137140
}

Submitted on 10 Feb 2021

HAL is a multi-disciplinary open access archive for the deposit and dissemination of scientific research documents, whether they are published or not. The documents may come from teaching and research institutions in France or abroad, or from public or private research centers.
L'archive ouverte pluridisciplinaire HAL, est destinée au dépôt et à la diffusion de documents scientifiques de niveau recherche, publiés ou non, émanant des établissements d'enseignement et de recherche français ou étrangers, des laboratoires publics ou privés. 


\title{
Fabrication and performance evaluation of reflectorless refractive index fiber optic sensors using etched enhanced backscattering fibers
}

\author{
A. Aitkulov ${ }^{\mathrm{a}, *}$, M. Sypabekova ${ }^{\mathrm{a}}$, C. Molardi ${ }^{\mathrm{a}}$, W. Blanc ${ }^{\mathrm{b}}, \mathrm{D} . \mathrm{Tosi}^{\mathrm{a}, \mathrm{c}}$ \\ ${ }^{a}$ Nazarbayev University, School of Engineering and Digital Sciences, 53 Kabanbay Batyr, 010000 Nur-Sultan, Kazakhstan \\ b Université Côte d'Azur, CNRS, INPHYNI, UMR 7010, Parc Valrose, 06108 Nice, France \\ ${ }^{\mathrm{c}}$ National Laboratory Astana, Laboratory of Biosensors and Bioinstruments, 53 Kabanbay Batyr, 010000 Nur-Sultan, Kazakhstan
}

\section{A R T I C L E I N F O}

\section{Keywords:}

Distributed sensing

Nanoparticle-doped fiber

Optical fiber sensor

Refractive index sensor

Optical backscatter reflectometry

\begin{abstract}
A B S T R A C T
We propose and evaluate a technique for the fabrication and interrogation of fiber-optic refractive index (RI) sensors based on etched MgO-based nanoparticle doped fibers. The discussed method does not require to inscribe a reflective element into the fiber. Instead, light backscattered by the fiber can give sufficient information that is necessary for detection, by performing the cross-correlation of Rayleigh scatter signatures in the etched zones. The performance of the sensor is monitored using distributed sensing, which allows to interrogate several points along the length of the fiber. The sensitivities of several etched fibers are compared. The largest sensitivity that has been achieved is $45.95 \mathrm{~nm} / \mathrm{RIU}$ (RI units), with the possibility of implementing temperature compensation.
\end{abstract}

\section{Introduction}

In recent years, optical fibers have become a valuable tool in the development of various sensors due to their miniature form factor, biocompatibility, immunity to electromagnetic interferences, and detection in multiple locations along the same fiber [1-3]. A very important area of optical fiber sensors technologies is represented by refractive index (RI) sensors [4,5]. RI sensors are an important tool in clinical diagnostic, medical instrumentation, industrial process control, agriculture, and environmental sciences [6]. A miniaturized fiber optic probe can measure the RI of liquid or oil solutions that comprise the surrounding environment of the sensor. The functionalization of a RI sensor using thin film coatings allows the design of accurate and selective optical biosensors with miniature size [6]. Another example is the implementation of DNA biosensors using microstructured optical fiber [7] and microfiber Bragg grating [8]. Photonic crystal fibers were used to create an interferometer that was able to detect Streptavidin and Biotin [9]. Surface plasmon resonance sensor capable of measuring ammonia gas concentration [10] was also reported. Another example of a sensor based on optical fibers is a configuration used to detect cholesterol, which was enhanced by golden nanoparticles [11].

Several technologies have been proposed for RI sensors based on optical fibers, using a robust and reliable spectral-based interrogation of the probe [6]. Most RI sensors can be divided into three areas, depending on the working principle. The first group of RI sensors and biosensors makes use of non-standard fiber Bragg gratings (FBG) inscribed in the fiber. The underlying principle is to modify the fiber structure so that the RI changes affect the waveguide properties, thus varying the effective RI of the fiber [12]. This principle is exploited by etched or thinned gratings [13-15] that encode the RI change in the Bragg wavelength, by tilted FBG $[16,17]$ that make use of RI-dependent cladding modes in the transmission spectrum, and by long period gratings $[18,19]$ that combine core and cladding transmission modes. Another method is the use of surface plasmon resonance (SPR) in a fiber: the p-polarized transmission spectra of a multimode fiber [20,21] or of a tilted FBG $[16,22]$ show RI-dependent wavelength shift with high sensitivity. A third method for RI sensors makes use of interferometers, such as single-multi-single mode fibers [23], Sagnac ring [24], or tapered fibers [25]. In these works, the RI variation is converted into a change of the optical path variation of the arms of an interferometer. The proposed RI sensors in general require the inscription of gratings into the optical fiber, or micro-machining of interferometers.

In this work, we propose an alternative concept labeled "reflectorless" sensor that does not need a grating to operate. Similar to the aforementioned approaches, the method involves the detection of the surrounding RI change by an etched fiber section. However, rather than encoding spectral features in the grating, they are encoded in the Rayleigh scattering signature that is already present in the fiber. In this sense, the "reflectorless" label means that the reflective element is a natural component of the fiber used for sensing, rather than an $a d-h o c$

\footnotetext{
* Corresponding author.

E-mail address: arman.aitkulov@nu.edu.kz (A. Aitkulov).
} 


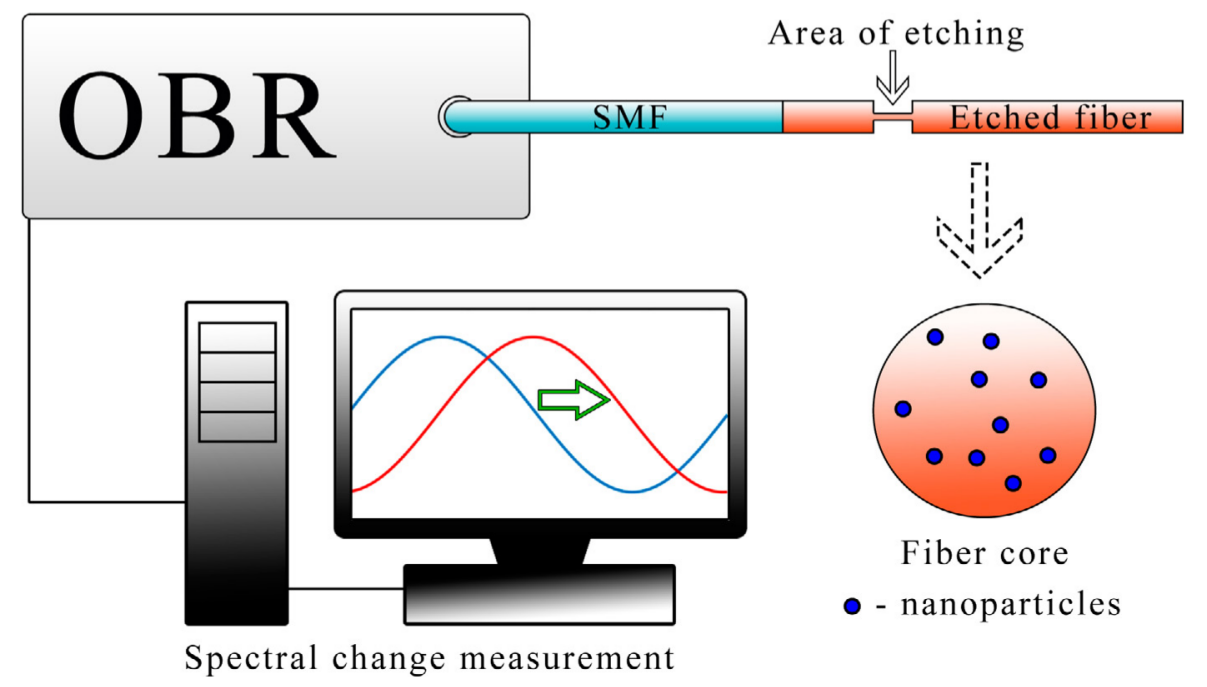

Fig. 1. Schematic of the measuring system.

device that the user needs to manufacture. As shown by Froggatt and Moore [26], the Rayleigh scattering of the fiber acts as a series of spectral signatures, emitted over the infrared bandwidth and detected with an optical backscattering reflectometer (OBR). From the optical point of view, the etched reflectorless sensor acts as an Iadicicco's thinned FBG [13] but without the grating, with similar sensitivity but different spectral features.

The main problem of this technology is that an etched standard single mode fiber (SMF), or a similar fiber, would not work in this architecture, because the backscattered power is not sufficient to sustain the evanescent wave losses, which are over $25 \mathrm{~dB}$ for a fiber with deep etching [27]. For this reason, the pivotal work proposed by Sypabekova et al. [28] made use of a fiber having a ring of nanoparticles around the core. As a result, the Rayleigh scattering was increased by a substantial amount, which was sufficient to detect a wavelength shift with resolution up to $1.53 \mathrm{~nm} / \mathrm{RIU}$ (refractive index units).

In this work, we propose a reflectorless RI sensor obtained by wetetching a fiber having the core doped with $\mathrm{MgO}$-based nanoparticles, which was done to increase the Rayleigh scattering component in fabrication. The approach is not based on conventional technologies of FBG. A similar setup was previously described in the work by Korganbayev et al. [27]. However, in the currently reported case, the fiber has been analyzed using distributed sensing in length domain reflectometry. With this solution, we demonstrate the possibility to achieve sensitivity equal to $45.95 \mathrm{~nm} / \mathrm{RIU}$, and report the sensitivity and performance of several sensors fabricated with this method. The fiber has been analyzed using distributed sensing in length domain reflectometry. The method allows to thoroughly interrogate a fiber link over a specified length [29] and identify the point with the highest level of sensitivity using only the information about light backscattered by the fiber.

\section{Experimental setup and fabrication}

\subsection{Experimental setup}

The fiber used in the experiments has been fabricated according to the previous work from Blanc et al. [30,31]. The fiber preform has been fabricated by MCVD (modified chemical vapor deposition), with a solution of $\mathrm{MgCl}_{2}$ added to the silica $\left(\mathrm{SiO}_{2}\right)$. The high-temperature phase occurring during the fiber drawing causes the separation of the alkaline ions from the silica, resulting in the formation of particles (20$100 \mathrm{~nm}$ diameter) within the fiber core. The particles are responsible for the increase of Rayleigh scattering. The fibers fabricated with this process have been designed to match the sizes of a standard telecom fibers (core diameter $10 \mu \mathrm{m}$, cladding diameter $125 \mu \mathrm{m}$, outer jacket $250 \mu \mathrm{m})$. Therefore, it is possible to make a lossless splice $(<0.1 \mathrm{~dB})$ between the high-scattering fiber and a standard SMF.

The schematic of the whole system is shown in Fig. 1. It simply includes the etched high-backscattering fiber, with a lead-in SMF, connected to an OBR (Luna OBR4600, Luna Inc., US). The minimalistic view of the sensing unit shows the concept of the reflectorless sensor, in which the entire sensing principle is encoded in the scattering analysis. The OBR measures the Rayleigh scattering signature of the reflected waves, in each location of the fiber. The changes of the Rayleigh scattering indicate alterations of the surrounding medium that need to be detected.

During the experiments, the fiber was interrogated using the OBR in distributed sensing mode. In this mode, the OBR processes points in a select region of the fiber in length domain (denoted as $z$ ). The light was scanned by the OBR in a range from 1525.0 to $1610.5 \mathrm{~nm}$. Gage length and resolution during the measurements were 0.5 and $0.1 \mathrm{~cm}$, respectively.

\subsection{Working principle}

The working principle of the RI sensor relies on changing the effective RI of an etched optical fiber by exposing it to the outer RI variation. This change is then converted to a wavelength shift. In order to evaluate this operation principle, we show in Fig. 2 the result of simulations performed on COMSOL Multiphysics, following the same method as in [32].

The first chart shows the effect of the etching process on the propagated fundamental mode. As the etching progresses, and the fiber becomes thinner, we observe that the outer borders of the mode shrink, causing a change of the confinement factor of the mode, and resulting in an effective refractive index change. The results of the simulations for 3 different RI values are shown in Fig. 2(b-c): as the diameter approaches $20 \mu \mathrm{m}$, we observe that the effective refractive index changes exponentially, and starts to diverge between each different curve.

By applying the OBR interrogation [26], and selecting one RI as reference, the change of RI induces a change of effective refractive index. An example of that is shown for the diameter change from 10.5 to $12.5 \mu \mathrm{m}$ in Fig. 2(c). Such change can be converted into a wavelength shift on the OBR [28], which is recorded by operating in distributed sensing mode.

The results obtained in Fig. 2 confirm a trend similar to an exponential function that relates the effective refractive index change 

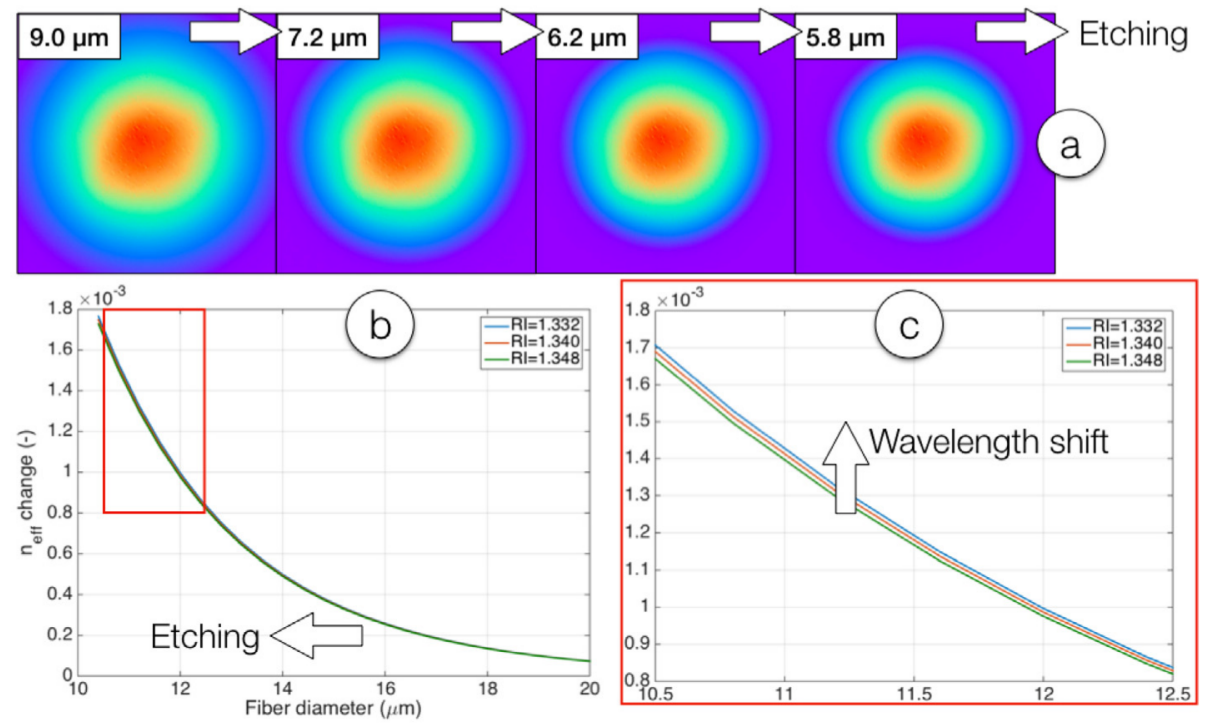

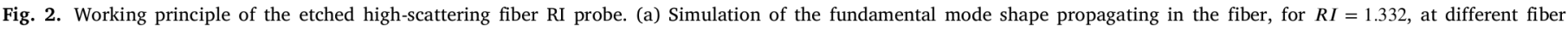

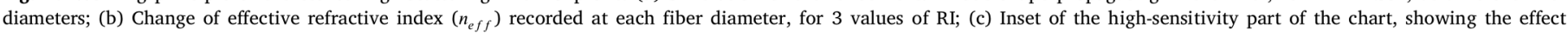
on wavelength shift.

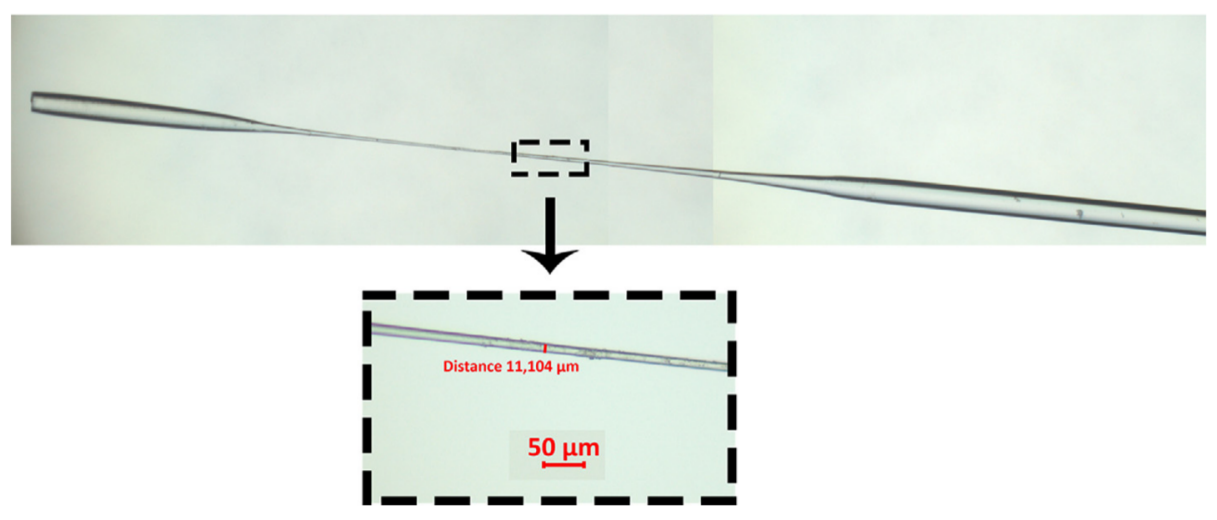

Fig. 3. Change in the diameter caused by etching.

and the reduction of the fiber diameter. This outcome is in agreement with the sensitivity models estimated for a single-mode etched FBG that have been proposed and experimentally validated by Kuhne et al. [33], hence showing that the presence of nanoparticles increases the Rayleigh scattering but still allows a significant dependence of the effective RI on the surrounding RI.

\subsection{Fiber preparation}

48\% hydrofluoric acid (HF) was used as an etching solution to narrow the diameter of a region on the fiber tip. As a result, the thickness of the cladding decreased over time, as shown in Fig. 3. The interaction between this exposed region and the surrounding environment leads to a formation of evanescent waves. If the RI of the external medium changes, the evanescent field also changes, affecting the effective RI of the etched fiber. Hence, the Rayleigh scattering signature of the fiber is altered, which can be detected by the OBR.

With this process, we fabricated 14 sensors. We report the most significant results for 4 sensors. Their traces in $z$-domain are shown in 4 , reporting the reflected signal to the OBR at each location. In each case, the power of the light reflected over a $1 \mathrm{~cm}$ region on the etched tip of the fiber was observed on the interrogator. In each graph, there is a sudden rise in amplitude from below $-90 \mathrm{~dB}$ to a level of approximately $-60 \mathrm{~dB}$. The scattering trace has a sawtooth shape, that was already observed in $[27,28]$. As the light enters into the highscattering fiber, we observe a substantial scattering increment (around $45 \mathrm{~dB})$. In cases from Fig. $4(\mathrm{c}, \mathrm{d})$, this gain is followed by an attenuation $(32.79 \mathrm{~dB} / \mathrm{m}$ and $67.57 \mathrm{~dB} / \mathrm{m}$, respectively). In cases from Fig. 4(a,b), the signals were not significantly attenuated due to the short lengths of the custom fibers. The gain provided by the custom fiber compensates for the losses caused by etching, which are visible in Fig. 4-inset in proximity of the region, and are only partially visible on the OBR due to the vicinity of the Fresnel reflection at the fiber tip, that accounts for the reflection spike at the fiber end.

By setting the OBR to acquire the Rayleigh signatures within the etched region and surrounding, it is possible to estimate then the wavelength shift for each signature within the etched area. Outside of the RI-sensitive etched zone, the fiber becomes unsensitive to the external RI. However, this portion of fiber can be used for temperature compensation. As shown in [28], the spatial resolution of the OBR is sufficient to resolve the wavelength shift in each etched portion without suffering from the Fresnel reflection on the tip.

The trace of the fiber that experienced etching in two points is shown in Fig. 4(c). Hence, contrary to the other three cases, two distinct amplitude spikes can be seen at the tip of the fiber instead of one. 
(a)

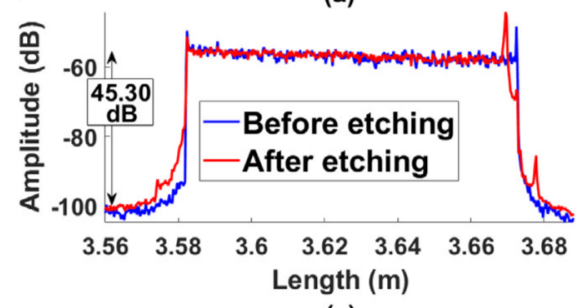

(c)

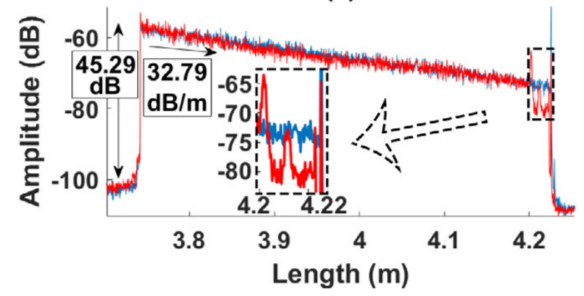

(b)

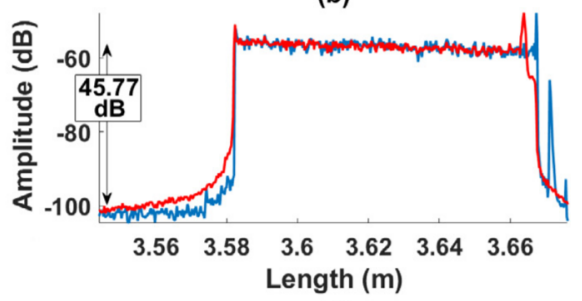

(d)

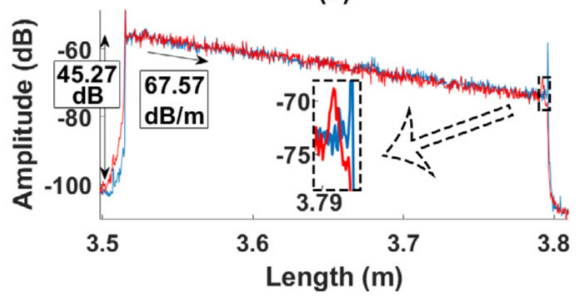

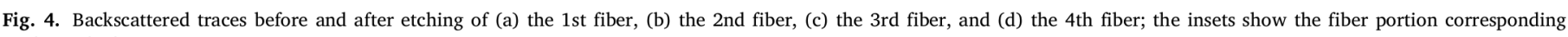
to the etched part.
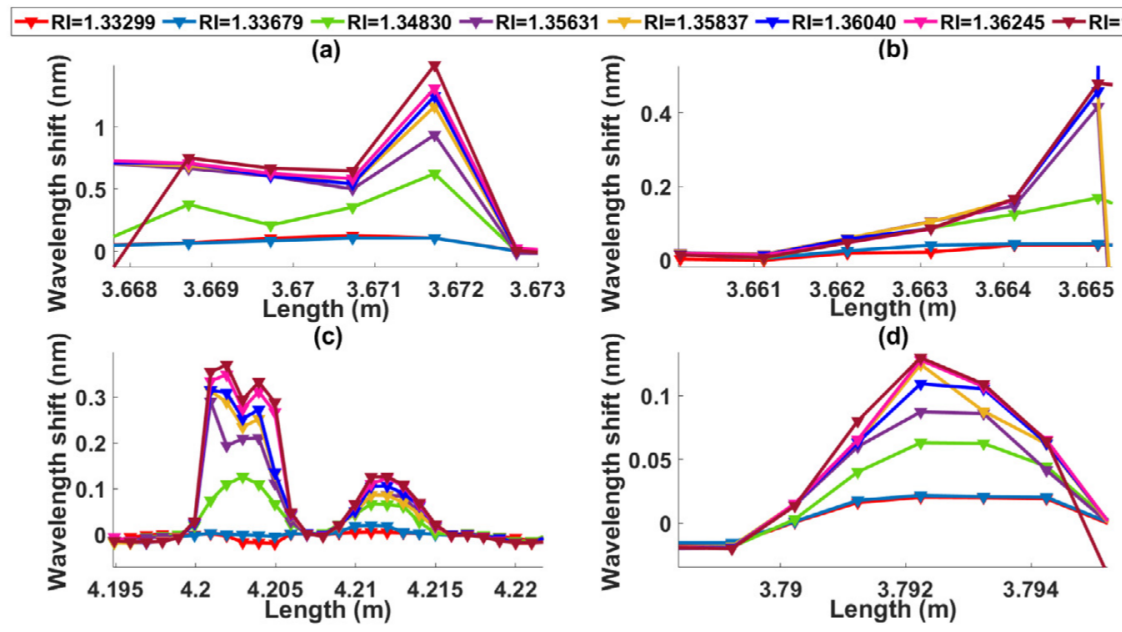

Fig. 5. Wavelength shifts for different RI values, recorded longitudinally on the etched portion of (a) the 1 st fiber, (b) the 2 nd fiber, (c) the 3 rd fiber, and (d) the 4th fiber.

\subsection{Data processing}

A change in the Rayleigh scattering signature considered in this work is the wavelength shift between the traces. Firstly, a portion around a specific point on the reference spectrum in $z$-domain is chosen. This particular region, defined by the value of gage length, is converted to wavelength domain $(\lambda)$. The procedure is repeated for a solution under analysis. After that, the cross-correlation of the resulting signal $(x)$ and the reference $(y)$ is obtained:

$R_{x y}(\lambda, z)=\sum_{\lambda} x(\lambda, z) \cdot y(\lambda, z)$

Then, the shift that results in the maximum value of the crosscorrelation is calculated [34]:

$\Delta \lambda_{e}(z)=\underset{\Delta \lambda(z)}{\arg \max } R_{x y}(\lambda-\Delta \lambda, z)$

The spectrum of the fiber immersed into water is taken as the reference. During the experiments, water has been consecutively replaced with solutions that have different RIs in order to test the sensor. The solutions were prepared by mixing different amounts of sucrose with water, according to the procedure described in [28]. The shifts recorded for each solution need to be plotted against the corresponding RIs. A relationship between $\Delta \lambda_{e}(z)$ and RI $\left(\Delta \lambda_{e}(z)=\gamma(R I, z)\right)$ is compared to a linear function ( $n$ is the amount of the tested solutions):

$\Delta \lambda_{f i t}(z)=a(z) \cdot R I+b(z)$

- where $a(z)$ and $b(z)$ are obtained through a common linear regression method.

The slope of the function in Eq. (3), $a(z)$, indicates the approximated sensitivity of the fiber. Hence, $a(z)$ is measured in nanometers per RI unit (nm/RIU). In addition, the coefficient of determination $\left(R^{2}(z)\right)$ needs to be found in order to define the quality of approximation provided by the fit:

$R^{2}(z)=\frac{\sum_{i=1}^{n}\left(\Delta \lambda_{f i t, i}(z)-\Delta \lambda_{e, \text { mean }}(z)\right)^{2}}{\sum_{i=1}^{n}\left(\Delta \lambda_{e, i}(z)-\Delta \lambda_{e, \text { mean }}(z)\right)^{2}}$

- where $\Delta \lambda_{e, \text { mean }}(z)$ is the average value of the shifts:

$$
\Delta \lambda_{e, \text { mean }}(z)=\frac{1}{n} \sum_{i=1}^{n} \Delta \lambda_{e, i}(z)
$$


(a)

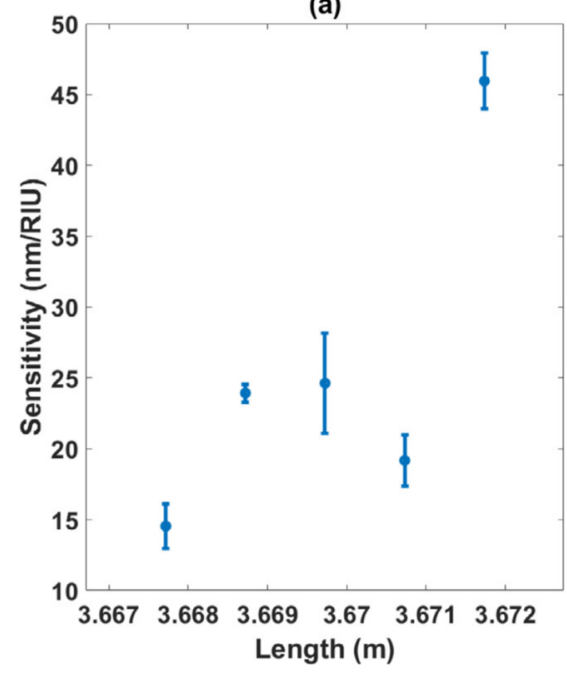

(b)

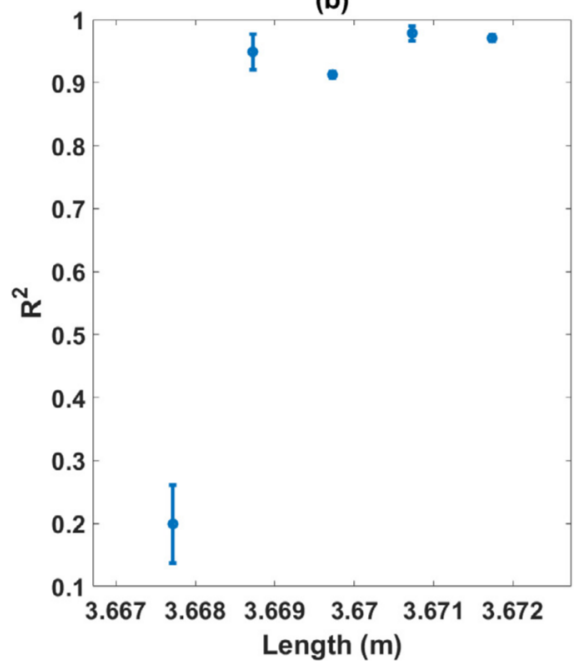

Fig. 6. (a) Sensitivity and (b) coefficient of determination obtained for the linear fit of the data at different points on the 1st fiber.

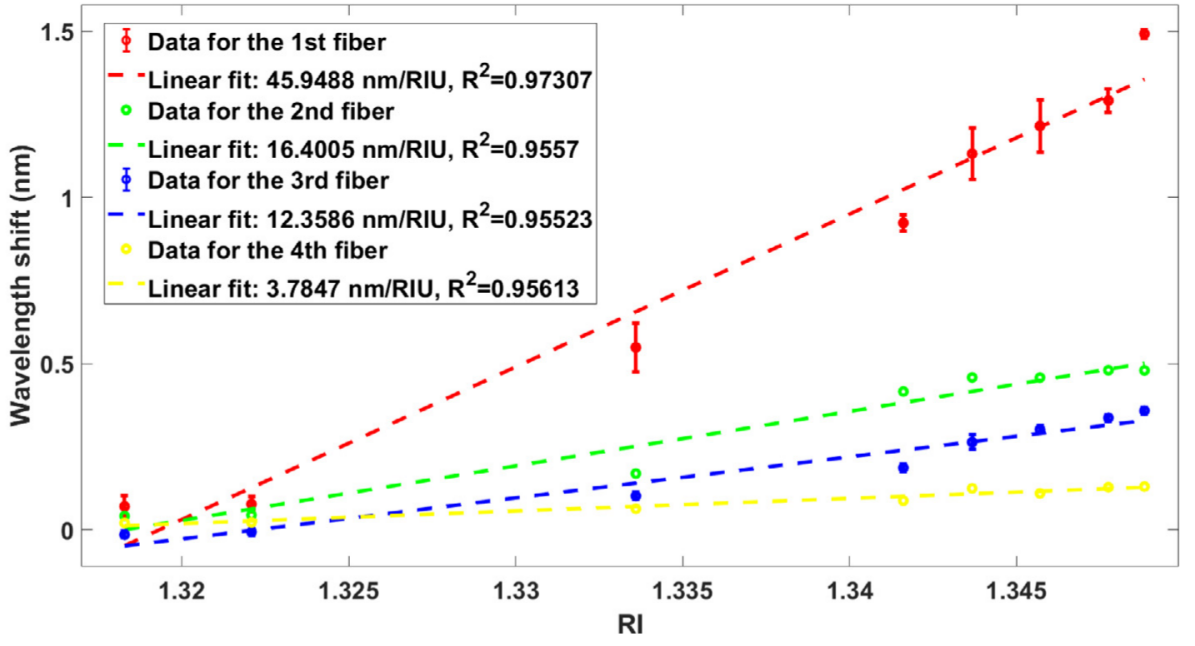

Fig. 7. Sensitivities obtained for the fibers.

\section{Results}

\subsection{Calibration and sensitivity analysis}

The fibers in Fig. 4 have been calibrated with 8 sucrose solutions of different RIs (1.33299, 1.33679, 1.34830, 1.35631, 1.35837, 1.36040, 1.36245, and 1.36353), which were estimated using a refractometer. The etching process increases the propagation losses, due to the evanescent wave losses in the etched region. However, the losses do not affect the wavelength shift estimation, as the cross-correlation peaks estimated in Eq. (2) do not depend on the level of the signals. The wavelength shifts were recorded for several points that comprise the ranges of interrogation up to the point where the fibers terminate, shown in Fig. 5. In certain regions, the shifts had become progressively larger as RI increased. Then, the values of the wavelength shifts were processed at each longitudinal point.

It is clear from Fig. 5 that the 1st fiber experienced the largest changes in the Rayleigh scattering as a result of exposure to different RIs, since the corresponding shifts reached a level higher than $1 \mathrm{~nm}$. In the case of the 2nd fiber (Fig. 5(b)), the highest shift was registered in a very close proximity of the tip. Hence, there was no descending pattern to the right of that point. The second largest value of shifts was registered for this fiber (around $0.4 \mathrm{~nm}$ ). The lowest shifts were observed in the case of the 4 th fiber.
The measurements of the shifts between the Rayleigh scattering signatures shown in Fig. 5(a) were repeated 3 times for each of the tested solutions. The resulting sensitivities and the coefficients of determination can be seen in Fig. 6(a, b). Variations across different trials are reflected in the values of standard deviation, which are plotted in the form of error bars. In all of the trials, the point at 3.6717 meters had the largest sensitivity, as well as an appropriate coefficient of determination. A trend followed by the shifts at this point is shown in Fig. 7. According to Fig. 4, the amplitude change there is equal to $-10.92 \mathrm{~dB}$. The second largest sensitivity with the proper $R^{2}(>0.9)$ value was $23.93 \mathrm{~nm} / \mathrm{RIU}$. It was found at $3.6690 \mathrm{~m}$, where the positive amplitude change of $8.37 \mathrm{~dB}$ was shown by the trace after etching.

The same solutions were also tested for the rest of the fibers. Similarly, the most sensitive points were identified. The results are summarized in Table 1 . The sensing range was defined as a range of points where sensitivity and $R^{2}$ were at least $1 \mathrm{~nm} / \mathrm{RIU}$ and $>0.9$, respectively. Trends, followed by the shifts at the most sensitive points of the fibers, are shown in Fig. 7.

The smallest sensing range, equal to $1 \mathrm{~mm}$, was determined for the 2nd fiber. In all of the other cases, it was $3 \mathrm{~mm}$. The explanation is that etching was done closer to the tip of the 2nd fiber, as it has been indicated previously when considering the shifts in Fig. 5. A smaller area of etching may also be a reason why the 2nd fiber is less sensitive 
(a)

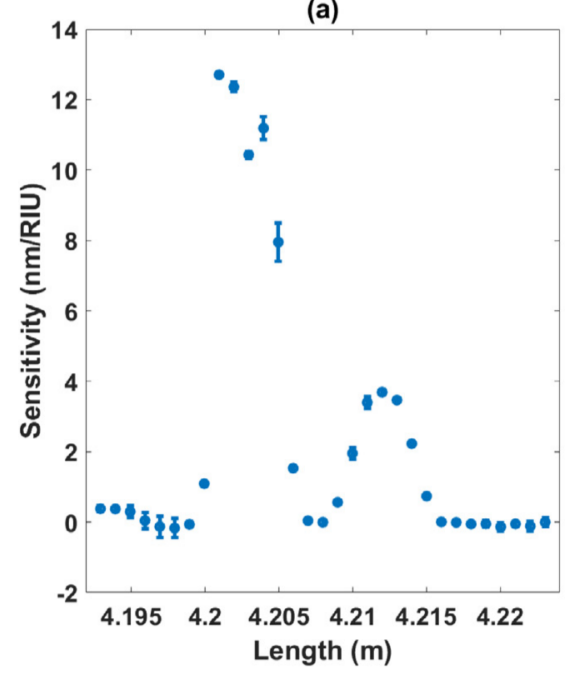

(b)

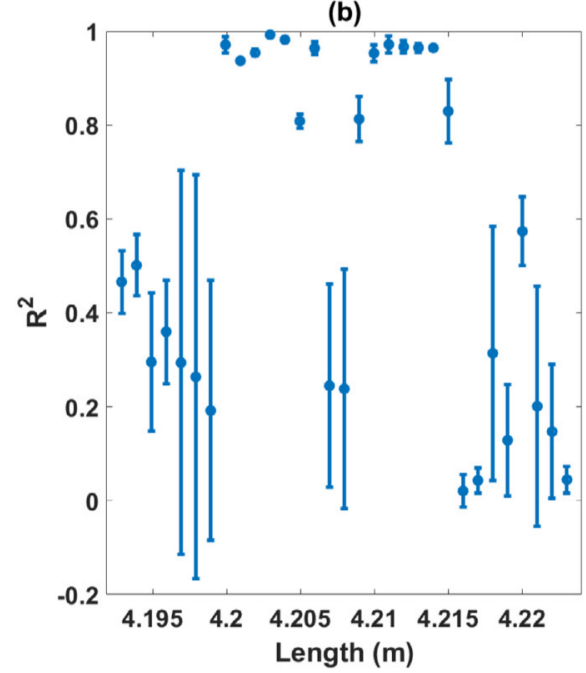

Fig. 8. (a) Sensitivity and (b) coefficient of determination obtained for the linear fit of the data at different points on the 3rd fiber.

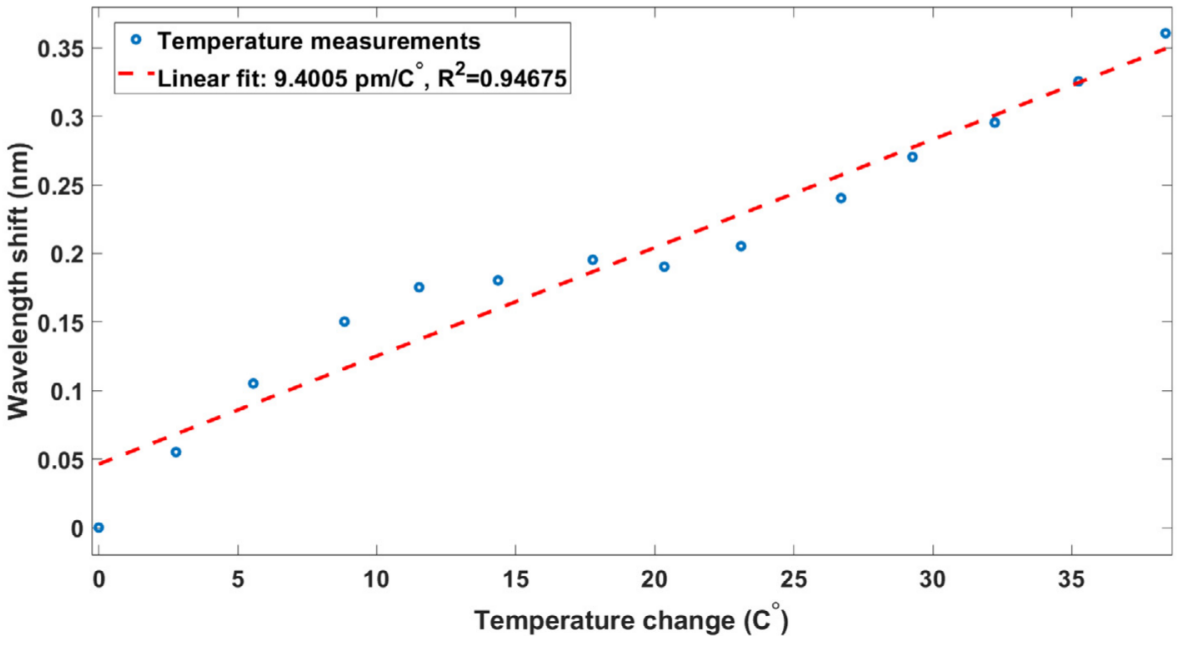

Fig. 9. Thermal calibration of the nanoparticle-doped fiber.

Table 1

Calibration data of 4 etched fibers.

\begin{tabular}{lllllll}
\hline $\begin{array}{l}\text { Fiber } \\
\text { № }\end{array}$ & $\begin{array}{l}\text { Most sensitive } \\
\text { point (m) }\end{array}$ & $\begin{array}{l}\text { Sensitivity } \\
(\mathrm{nm} / \mathrm{RIU})\end{array}$ & $R^{2}$ & $\begin{array}{l}\text { Sensing } \\
\text { range (m-m) }\end{array}$ & $\begin{array}{l}\text { Scattering } \\
\text { gain }(\mathrm{dB})\end{array}$ & $\begin{array}{l}\text { Two-way fiber } \\
\text { losses }(\mathrm{dB} / \mathrm{m})\end{array}$ \\
\hline $\mathbf{1}$ & 3.6717 & 45.95 & 0.97 & $3.669-3.672$ & 45.30 & - \\
2 & 3.6651 & 16.40 & 0.96 & $3.664-3.665$ & 45.77 & - \\
3 & 4.2019 & 12.36 & 0.96 & $4.201-4.204$ & 45.29 & 32.79 \\
4 & 3.7922 & 3.78 & 0.96 & $3.791-3.794$ & 45.27 & 67.57 \\
\hline
\end{tabular}

than the 1st fiber. Smaller sensitivities of the 3rd and the 4th fibers can be attributed to the attenuation of the fiber, which was negligible in the other two fibers due to their short length.

\subsection{Multiple etching}

We performed an experiment aimed at verifying the possibility of fabricating multiple sensitive regions on the same fibers, in order to test the possibility of detecting multiple analytes with a single probe [35]. In order to validate this feature, we performed etching in 2 distinct regions of a high-scattering fiber, and the local wavelength shift sensitivity to RI is reported in Fig. 5(c). We can notice that the RI sensing is mainly implemented in two distinct regions on the fiber (at $4.202 \mathrm{~m}$ and $4.212 \mathrm{~m}$ ). The observation is supported by the data summarized in Fig. 8 that shows two regions with $R^{2}>0.9$. The largest sensitivity, equal to $12.36 \mathrm{~nm} / \mathrm{RIU}$, was achieved in the first region of etching. In the second region, the most sensitive point ( $3.69 \mathrm{~nm} / \mathrm{RIU})$ was at $4.2120 \mathrm{~m}$. This figure shows the possibility of detecting 2 independent RI values on the same fiber, with a multifunctional probe.

\subsection{Thermal characterization}

A thermal characterization of the unetched fiber has been carried out to evaluate the relationship between wavelength shift and temperature, shown in Fig. 9. The fiber was immersed into water that had been gradually heated. Temperature measurements taken by the standard fiber with 5 FBGs were used as a reference. Then, the sensitivity of 9.4 $\mathrm{pm} / \mathrm{C}^{\circ}$ was defined by matching the temperatures with the respective wavelength shifts.

While the etched region of the fiber is RI-sensitive, the unaltered regions preserve the initial sensitivity of the fiber. Hence, we can compensate the temperature by measuring the wavelength shift outside of the etched region and subtracting it from the wavelength shift detected at the point of the maximum RI sensitivity.

\section{Conclusions}

The reflectorless sensing configuration based on optical fiber was presented in this work, forming a minimalistic implementation of a RI 
sensor that does not require any grating, resonance, or interferometer. The fiber is simply manufactured by wet-etching, a process common in large-scale electronic manufacturing and therefore industrially scalable. All the sensing information is encoded in the Rayleigh scattering signatures, which acts are already present in the fiber. In order to compensate the fiber evanescent-wave losses, the fiber chosen in the experiment is a high-scattering fiber having the core that was doped with MgO-based nanoparticles, which allows a scattering increment of $45 \mathrm{~dB}$.

The etched MgO-NP RI sensor proposed in this work has performance and behavior that depends on the geometrical properties of the fiber. The fiber thickness controls the sensitivity of the sensor, and reflects on the propagation losses and the tensile strength of the sensor.

The proposed sensing system was tested on four different etched fibers, with sensitivity ranging from $3.78 \mathrm{~nm} / \mathrm{RIU}$ to $45.95 \mathrm{~nm} / \mathrm{RIU}$. We also present a possible extension of the sensing region to multiple etched regions for a multiplexed sensor. The result is a 30-fold increase of sensitivity with respect to [28], with an RI sensitivity that even overcomes etched or tilted FBG sensors [27]. Besides, the fiber has twoway losses almost 50 times lower than [28], which makes it a good candidate to be connected to the OBR without any intermediate SMF spans. The OBR-based interrogation resolves the RI in multiple points, and the sensitivity and $R^{2}$ analysis allows identifying the most reliable and sensitive point of detection.

The novelty of the approach is that it does not require to inscribe additional reflective elements into the fiber. As Rayleigh scattering is already a feature of the fiber, and the fiber can be manufactured with a process similar to telecom fibers, such a minimalistic architecture allows high sensitivity and ease of manufacturing. Future work will address the biofunctionalization of the structure for biological sensing, and the further optimization of the scattering properties. The etching at several points along the fiber could open the possibility of measuring two analytes at the same time for biosensing purposes.

\section{CRediT authorship contribution statement}

A. Aitkulov: Data curation, Formal analysis, Software, Visualization, Writing - original draft, Writing - review \& editing. M. Sypabekova: Investigation, Writing - review \& editing. C. Molardi: Methodology, Writing - review \& editing. W. Blanc: Funding acquisition, Resources, Writing - review \& editing. D. Tosi: conceptualization, Funding acquisition, Project administration, Resources, Supervision, Writing - review \& editing.

\section{Declaration of competing interest}

The authors declare that they have no known competing financial interests or personal relationships that could have appeared to influence the work reported in this paper.

\section{Funding}

The data analysis, investigation and preparation of results were conducted as a part of the research funded by Nazarbayev University, Kazakhstan, under grants EPICGuide (code: 240919FD3908) and SMARTER (code: 091019CRP2117). The fiber was fabricated as a part of the work supported by ANR Projects Nice-DREAM, France (ANR-14CE07-0016-03) and NanoSlim, France (ANR-17-CE08-0002).

\section{References}

[1] B. Lee, Review of the present status of optical fiber sensors, Opt. Fiber Technol., Mater. Devices Syst. 9 (2) (2003) 57-79, http://dx.doi.org/10.1016/S10685200(02)00527-8.

[2] V. Mishra, N. Singh, U. Tiwari, P. Kapur, Fiber grating sensors in medicine: Current and emerging applications, Sensors Actuators A 167 (2) (2011) 279-290, http://dx.doi.org/10.1016/j.sna.2011.02.045.
[3] D. Tosi, E. Schena, C. Molardi, S. Korganbayev, Fiber optic sensors for subcentimeter spatially resolved measurements: Review and biomedical applications, Opt. Fiber Technol., Mater. Devices Syst. 43 (2018) 6-19, http://dx.doi.org/10. 1016/j.yofte.2018.03.007.

[4] W. Liang, Y. Huang, Y. Xu, R.K. Lee, A. Yariv, Highly sensitive fiber Bragg grating refractive index sensors, Appl. Phys. Lett. 86 (15) (2005) 151122, http://dx.doi.org/10.1063/1.1904716.

[5] I.M. White, X. Fan, On the performance quantification of resonant refractive index sensors, Opt. Express 16 (2) (2008) 1020-1028, http://dx.doi.org/10. 1364/OE. 16.001020.

[6] A.B. Socorro-Leranoz, D. Santano, I.D. Villar, I.R. Matias, Trends in the design of wavelength-based optical fibre biosensors (2008-2018), Biosens. Bioelectron. X 1 (2019) 100015, http://dx.doi.org/10.1016/j.biosx.2019.100015.

[7] D. Passaro, M. Foroni, F. Poli, A. Cucinotta, S. Selleri, J. Lægsgaard, A.O. Bjarklev, All-silica hollow-core microstructured Bragg fibers for biosensor application, IEEE Sens. J. 8 (7) (2008) 1280-1286, http://dx.doi.org/10.1109/JSEN. 2008.926969.

[8] D. Sun, T. Guo, B.-O. Guan, Label-free detection of DNA hybridization using a reflective microfiber Bragg grating biosensor with self-assembly technique, J. Lightwave Technol. 35 (16) (2017) 3354-3359, http://dx.doi.org/10.1109/JLT. 2017.2659778.

[9] D.J.J. Hu, J.L. Lim, M.K. Park, L.T.-H. Kao, Y. Wang, H. Wei, W. Tong, Photonic crystal fiber-based interferometric biosensor for streptavidin and biotin detection, IEEE J. Sel. Top. Quantum Electron. 18 (4) (2012) 1293-1297, http://dx.doi.org/ 10.1109/JSTQE. 2011.2169492.

[10] S.K. Mishra, S. Bhardwaj, B.D. Gupta, Surface plasmon resonance-based fiber optic sensor for the detection of low concentrations of ammonia gas, IEEE Sens. J. 15 (2) (2015) 1235-1239, http://dx.doi.org/10.1109/JSEN.2014.2356251.

[11] S. Kumar, R. Singh, B.K. Kaushik, N.-K. Chen, Q.S. Yang, X. Zhang, LSPR-based cholesterol biosensor using hollow core fiber structure, IEEE Sens. J. 19 (17) (2019) 7399-7406, http://dx.doi.org/10.1109/JSEN.2019.2916818.

[12] T. Erdogan, Fiber grating spectra, J. Lightwave Technol. 15 (8) (1997) 1277-1294, http://dx.doi.org/10.1109/50.618322.

[13] A. Iadicicco, A. Cusano, S. Campopiano, A. Cutolo, M. Giordano, Thinned fiber Bragg gratings as refractive index sensors, IEEE Sens. J. 5 (6) (2005) 1288-1295, http://dx.doi.org/10.1109/JSEN.2005.859288.

[14] A. Iadicicco, S. Campopiano, A. Cutolo, M. Giordano, A. Cusano, Nonuniform thinned fiber Bragg gratings for simultaneous refractive index and temperature measurements, IEEE Photonics Technol. Lett. 17 (7) (2005) 1495-1497, http: //dx.doi.org/10.1109/LPT.2005.848282.

[15] A. Bekmurzayeva, K. Dukenbayev, M. Shaimerdenova, I. Bekniyazov, T. Ayupova, M. Sypabekova, C. Molardi, D. Tosi, Etched fiber Bragg grating biosensor functionalized with aptamers for detection of thrombin, Sensors 18 (12) (2018) 4298, http://dx.doi.org/10.3390/s18124298.

[16] J. Albert, L.Y. Shao, C. Caucheteur, Tilted fiber Bragg grating sensors, Laser Photonics Rev. 7 (1) (2013) 83-108, http://dx.doi.org/10.1002/lpor.201100039.

[17] M. Sypabekova, S. Korganbayev, Álvaro González-Vila, C. Caucheteur, M. Shaimerdenova, T. Ayupova, A. Bekmurzayeva, L. Vangelista, D. Tosi, Functionalized etched tilted fiber Bragg grating aptasensor for label-free protein detection, Biosens. Bioelectron. 146 (2019) http://dx.doi.org/10.1016/j.bios.2019.111765.

[18] S.M. Tripathi, W.J. Bock, P. Mikulic, R. Chinnappan, A. Ng, M. Tolba, M. Zourob, Long period grating based biosensor for the detection of Escherichia coli bacteria, Biosens. Bioelectron. 35 (1) (2012) 308-312, http://dx.doi.org/10.1016/j.bios. 2012.03.006.

[19] L. Marques, F.U.H. Ledezma, S. James, S.P. Morgan, M. Clark, R.P. Tatam, S. Korposh, Highly sensitive optical fibre long period grating biosensor anchored with silica core gold shell nanoparticles, Biosens. Bioelectron. 75 (2016) 222-231, http://dx.doi.org/10.1016/j.bios.2015.08.046.

[20] A.K. Sharma, R. Jha, B.D. Gupta, Fiber-optic sensors based on surface plasmon resonance: a comprehensive review, IEEE Sens. J. 7 (8) (2007) 1118-1129, http://dx.doi.org/10.1109/JSEN.2007.897946.

[21] Q. Wang, B. Sun, E. Hu, W. Wei, Cu/ITO-coated uncladded fiber-optic biosensor based on surface plasmon resonance, IEEE Photonics Technol. Lett. 31 (14) (2019) 1159-1162, http://dx.doi.org/10.1109/LPT.2019.2908288.

[22] C. Caucheteur, Y. Shevchenko, L.Y. Shao, M. Wuilpart, J. Albert, High resolution interrogation of tilted fiber grating SPR sensors from polarization properties measurement, Opt. Express 19 (2) (2011) 1656-1664, http://dx.doi.org/10. 1364/OE.19.001656.

[23] P. Wang, G. Brambilla, M. Ding, Y. Semenova, Q. Wu, G. Farrell, Investigation of single-mode-multimode-single-mode and single-mode-tapered-multimode-singlemode fiber structures and their application for refractive index sensing, J. Opt. Soc. Amer. B 28 (5) (2011) 1180-1186, http://dx.doi.org/10.1364/JOSAB.28. 001180.

[24] S. Gao, L.P. Sun, J. Li, L. Jin, Y. Ran, Y. Huang, B.O. Guan, High-sensitivity DNA biosensor based on microfiber Sagnac interferometer, Opt. Express 25 (12) (2017) 13305-13313, http://dx.doi.org/10.1364/OE.25.013305. 
[25] J.M. Corres, I.R. Matias, J. Bravo, F.J. Arregui, Tapered optical fiber biosensor for the detection of anti-gliadin antibodies, Sensors Actuators B 135 (1) (2008) 166-171, http://dx.doi.org/10.1016/j.snb.2008.08.008.

[26] M. Froggatt, J. Moore, High-spatial-resolution distributed strain measurement in optical fiber with Rayleigh scatter, Appl. Opt. 37 (10) (1998) 1735-1740, http://dx.doi.org/10.1364/AO.37.001735.

[27] S. Korganbayev, M. Shaimerdenova, T. Ayupova, M. Sypabekova, A. Bekmurzayeva, W. Blanc, C. Molardi, D. Tosi, Refractive index sensor by interrogation of etched MgO nanoparticle-doped optical fiber signature, IEEE Photonics Technol. Lett. 31 (15) (2019) 1253-1256, http://dx.doi.org/10.1109/LPT.2019.2924652.

[28] M. Sypabekova, S. Korganbayev, W. Blanc, T. Ayupova, A. Bekmurzayeva, M. Shaimerdenova, K. Dukenbayev, C. Molardi, D. Tosi, Fiber optic refractive index sensors through spectral detection of Rayleigh backscattering in a chemically etched MgO-based nanoparticle-doped fiber, Opt. Lett. 43 (24) (2018) 5945-5948, http://dx.doi.org/10.1364/OL.43.005945.

[29] M.K. Saxena, J. Raju, R. Arya, R.B. Pachori, S. Kher, Instantaneous area based online detection of bend generated error in a Raman optical fiber distributed temperature sensor, IEEE Sens. Lett. 1 (4) (2017) http://dx.doi.org/10.1109/ LSENS.2017.2726690.
[30] W. Blanc, C. Guillermier, B. Dussardier, Composition of nanoparticles in optical fibers by secondary ion mass spectrometry, Opt. Mater. Express 2 (11) (2012) 1504-1510, http://dx.doi.org/10.1364/OME.2.001504.

[31] W. Blanc, B. Dussardier, Formation and applications of nanoparticles in silica optical fibers, J. Opt. 45 (3) (2015) 247-254, http://dx. doi.org/10.1007/s12596015-0281-6.

[32] T. Ayupova, M. Shaimerdenova, S. Korganbayev, M. Sypabekova, A. Bekmurzayeva, W. Blanc, S. Sales, T. Guo, C. Molardi, D. Tosi, Fiber optic refractive index distributed multi-sensors by scattering-level multiplexing with $\mathrm{MgO}$ nanoparticledoped fibers, IEEE Sens. J. 20 (5) (2019) 2504-2510, http://dx.doi.org/10.1109/ JSEN.2019.2953231.

[33] J.F. Kuhne, A.M. Rocha, R.C. Barreto, R.C. Kamikawachi, Estimation models for the refractive index response curve of efbgs, IEEE Sens. J. 20 (22) (2020) 13394-13402, http://dx.doi.org/10.1109/JSEN.2020.3005596.

[34] D. Tosi, Review and analysis of peak tracking techniques for fiber Bragg grating sensors, Sensors 17 (10) (2017) 2368, http://dx.doi.org/10.3390/s17102368.

[35] C. Fallauto, Y. Liu, G. Perrone, A. Vallan, Compensated surface plasmon resonance sensor for long-term monitoring applications, IEEE Trans. Instrum. Meas. 63 (5) (2013) 1287-1292, http://dx.doi.org/10.1109/TIM.2013.2286956. 